\title{
Dental anxiety in patients referring to dental clinics differs between women and men in Ahvaz city, Iran
}

\author{
Elaheh Mali ${ }^{1}$, Fatemeh Babadi², Maria Cheraghi ${ }^{3}$ \\ ${ }^{1}$ Department of Community Oral Health, School of Dentistry, Ahvaz Jundishapur University of Medical Sciences, Ahvaz, Iran \\ ${ }^{2}$ Department of Oral and Maxillofacial Medicine, School of Dentistry, Ahvaz Jundishapur University of Medical Sciences, Iran \\ ${ }^{3}$ Social Determinants of Health Research Center, Department of Community Oral Health, School of Dentistry, Ahvaz \\ Jundishapur University of Medical Sciences, Ahvaz, Iran
}

Neuropsychiatria i Neuropsychologia 2021; 16, 3-4: 155-160

Address for correspondence:

Maria Cheraghi, PhD

Social Determinants of Health Research Center

Department of Community Oral Health

School of Dentistry

Ahvaz Jundishapur University of Medical Sciences

Ahvaz, Iran

e-mail: mariacheraghi@gmail.com

\section{Abstract}

Introduction: Dental anxiety reduces the level of oral health and quality of life. We aimed to assess anxiety in patients referring to dental clinics differs among women and men in Ahvaz city, Iran.

Material and methods: It was a descriptive-analytical study conducted on 397 patients who had referred to dental clinics in Ahvaz city, 2020. The patients were selected using a non-random sampling method. The administered instruments included the Demographic Variables Questionnaire and the Dental Anxiety Inventory. Descriptive statistics were applied to describe the participants' characteristics using, mean, and standard deviation. Kolmogorov-Smirnov tests was run to assess data distribution. Furthermore, to determine the relationship between variables, independent $t$-test and one-way analysis of variance were used. Data has entered and analyzed by using SPSS software version. Lever of significant was considered less than 0.05 .

Results: Findings of the study showed that the mean and standard deviation of the dental anxiety scores was $87.51 \pm 30.64$ (scores ranged from 36 to 180 ). Based on the results, $38 \%$ of the participants were men $(n=151)$ and $62 \%$ were women $(n=246)$. The mean age of participants was 41.7 years with a minimum of 18 years. The relationship between anxiety and gender was statistically significant $(p<0.01)$. The mean scores of anxiety had no significant difference with regard to the variables of age, education, type of employment, ethnicity, or number of referrals $(p<0.05)$.

Conclusions: The level of dental anxiety was significantly different among the patients considering their gender, so that women tolerated higher levels of anxiety. Authorities are suggested to prioritize their interventions to manage dental anxiety with the priority of women.

Key words: dental, anxiety, patients, Ahvaz.

\section{Introduction}

Dental anxiety is one of the important reasons for patients to refrain from referring to dental service centers, which leads to deterioration of oral health and quality of life and depression among people (Saberi and Nahash 2018). This anxiety is sometimes accompanied by much fear and panic in patients that deprives dentists of the opportunity to provide any kind of services (Gelder et al. 2009). In general definitions, anxiety is an imaginary threat from an unknown and unfamiliar phenomenon that arises from expectation of an undesirable event by individuals (Mohammed et al. 2014). In fact, many people experience dental anxiety as a reaction to an unknown danger, especially when they have not experienced it before (Bracha et al. 2006). Most anxious people associate dentistry with pain, which is one of the factors affecting the increase of psychological reactions to pain and its transmission (Cheraghi et al. 2015; Gelder et al. 2009). Moreover, recurrence of these anxious reactions during the examination or treatment process affects dentists and reduces their efficiency (Saberi and Nahash 2018).

According to worldwide research, dental anxiety is a common phenomenon. For example, the prevalence of dental anxiety was $14.9 \%$ in 
the young adult population in Australia, while it was $12.5 \%$ in Canada, and $12.6 \%$ in Russia (Udoye et al. 2005; Saatchi et al. 2015). In other words, most studies estimated the prevalence of dental anxiety within the range of $2.5 \%$ to 19\% (Saberi and Nahash 2018). Feelings of anxiety, fear, and pain caused by dental treatments play an important role in the dentistpatient relationship, which in turn influences the choice and design of treatments (Fayad et al. 2017). Dental anxiety gradually weakens the oral health and has negative effects on patients' quality of social life. It also leads to dissatisfaction of patients during the treatment (Saatchi et al. 2015). Investigation of dental anxiety and its related factors is one of the ways to improve the quality of patients' treatment (Muhannad et al. 2020); however, routinizing such assessments has its own challenges and limitations (Tellez et al. 2015).

Based on the available evidence, a statistically significant relationship exists between dental anxiety and low levels of life satisfaction (Tellez et al. 2015). Some studies indicated that this type of anxiety is directly related to all social relationships and their mental states (Saberi and Nahash 2018). According to the DSM-IV index, this type of anxiety is a type of phobia in patients that can lead to panic attacks in people prone to social phobia and other phobias (Halonen $e t$ al. 2018; Tellez et al. 2015). Even in some studies, the cause of anxiety was associated with bad memories of the past treatments (Halonen $e t$ al. 2018). According to some reports, dental anxiety is associated with factors such as age, education, gender, and socio-economic status (Fayad et al. 2017).

To observe oral health as a factor having a strong influence on the population's general health, people are required to refer to dentists in dental clinics for periodic examinations and treatments (Saberi and Nahash 2018). So, dentists should be able to diagnose the level of anxiety in individuals before treatment and plan an appropriate treatment program according to their level of anxiety (Saatchi et al. 2015). However, it is not clear how dentists should manage this challenge since no specific solutions are available from the scope of psychology or psychiatry for potential interventions in this regard (Halonen et al. 2018). Various studies have placed special emphasis on the study of dental anxiety and its related factors as the first step in planning interventions (Mehrstedt et al. 2004; Addicks et al. 2017; Muhannad et al. 2020). Given that the level of anxiety and its causes are different in various societies and ethnicities and no research has ever investigated the status of dental anxiety in Ahvaz, this study was conducted. The aim was to assess anxiety and its related factors in patients who referred to clinics in Ahvaz city during 2020.

\section{Material and methods}

\section{Study area}

The study was carried out in Ahvaz city in Khuzestan metropolis in southwestern of Iran, with a citizen count of $\sim 1.3$ million and situated at $31^{\circ} 19^{\prime} 13^{\prime \prime} \mathrm{N}$ and $48^{\circ} 40^{\prime} 09^{\prime \prime} \mathrm{E}$ (Fig. 1) (Goudarzi et al. 2019; Jamshidi et al. 2016). The temperature sometimes exceeds $50^{\circ} \mathrm{C}$ during summers and the humidity on some days reaches more than $90 \%$.

\section{Participants and implementation method}

This descriptive-analytical research was conducted to determine the level of anxiety in patients who referred to dental clinics in Ahvaz city, Iran, 2020. The studied clinics, located in Khuzestan province, Ahvaz city in the southwest of Iran, are affiliated to Jundishapur University of Medical Sciences. Yaghooti Khorasani et al. (2014) estimated the sample size as 368 people considering the probability of dental anxiety prevalence as $40 \%(\mathrm{P})$, study accuracy of $0.05(\mathrm{~d})$, and confidence coefficient of $2 \%(\mathrm{Z} 1-\alpha 2.1=96.1)$ :

$$
\left(n=\frac{z_{\left(1-\frac{\alpha}{2}\right)}^{2} P(1-P)}{d^{2}}\right) .
$$

Finally, due to the possible loss of samples and increase of accuracy in the study, 397 people entered the study.

By attending dental clinics and ensuring observance of the inclusion criteria in Table 1, eligible individuals were selected to enter the study. The research questionnaires were completed by the patients, their companions, or the researcher.

\section{Research tools}

The study instruments included the Demographic Variables Questionnaire (age, gender, education, marital status, and employment) and Dental Anxiety Inventory (DAI). This questionnaire consists of 36 questions related to the causes of dental anxiety in individuals. Stouthard et al. (1990) calculated internal consistency of this scale as 0.96-0.98 using Cronbach's $\alpha$. They also reported that its reliability 


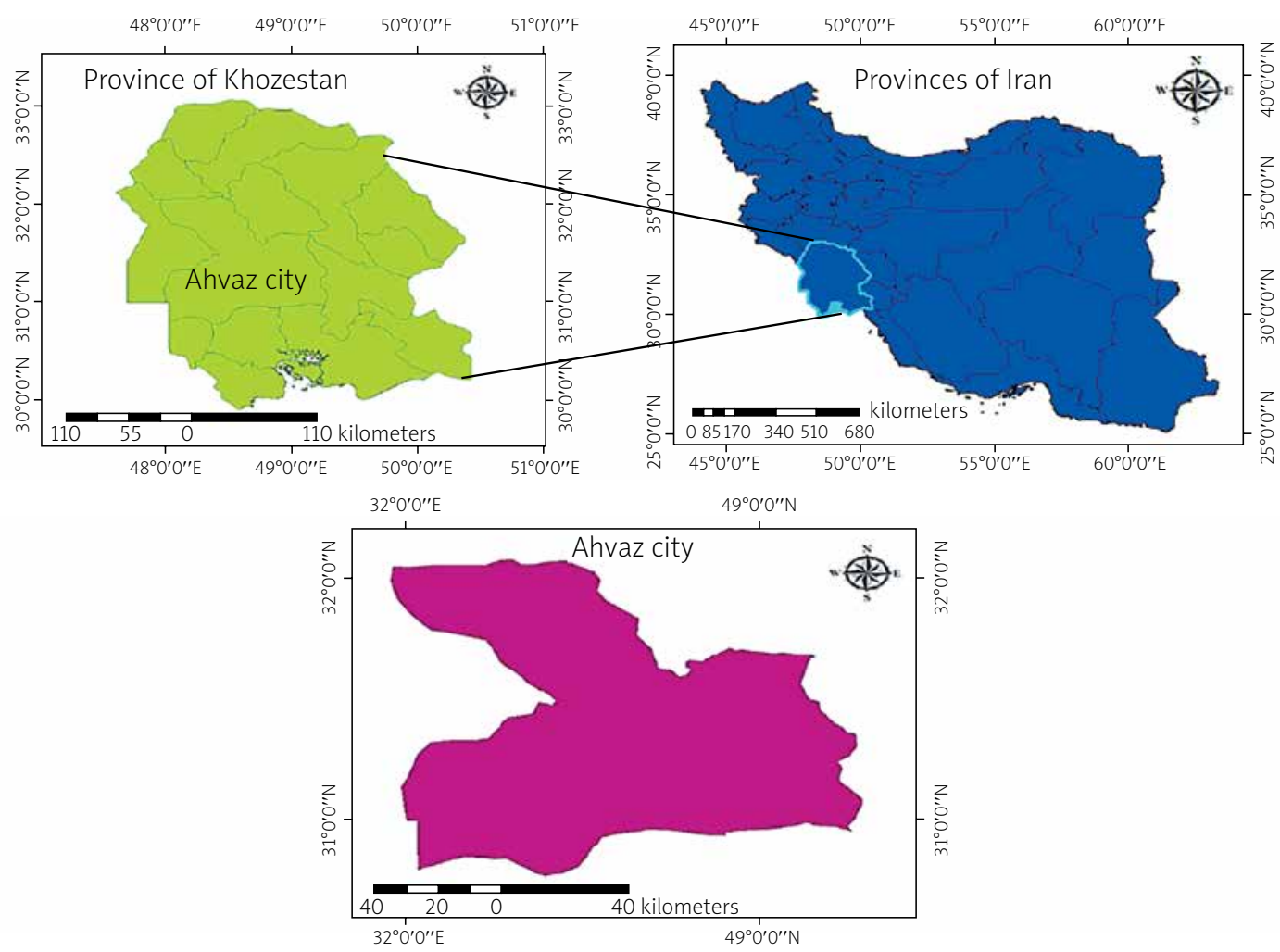

Fig. 1. Location of Ahvaz city (Goudarzi et al. 2019)

was within the range of 0.84-0.88 in different groups using the test-retest method. In Iran, Yousefi and Piri investigated the reliability of DAI via internal consistency and test-retest methods. As they reported, both methods resulted in similar findings confirming optimal reliability of this questionnaire. Items of this questionnaire should be scored on a five-point Likert scale, ranging from 1 (completely disagree) to 5 (completely agree). The attainable scores from this questionnaire are within the range of 36 to 180 , where higher scores represent higher levels of dental anxiety.

\section{Data analysis}

Descriptive statistics were applied to describe the participants' characteristics using, mean, and standard deviation. Kolmogorov-Smirnov tests was run to assess data distribution. Furthermore, to determine the relationship between variables, independent $t$-test and one-way analysis of variance were used. Data has entered and analyzed by using SPSS software version. Lever of significant was considered less than 0.05 .

\section{Results}

In the present study, the participants included $38 \%$ men $(n=151)$ and $62 \%$ women $(n=246)$. The mean age of participants was 41.7 years with
Table 1. Inclusion and exclusion criteria

\begin{tabular}{ll} 
Inclusion criteria & $\begin{array}{l}\text { 1. Patients referred to the dental } \\
\text { department }\end{array}$ \\
& $\begin{array}{l}\text { 2. Those who had informed consent } \\
\text { to participate in the study }\end{array}$ \\
\hline 3. No mental health problems \\
\hline Exclusion criteria & $\begin{array}{l}\text { Patients who did not cooperate and } \\
\text { incomplete information }\end{array}$ \\
\hline
\end{tabular}

a minimum of 18 years. Based on the findings, the mean score of dental anxiety was 87.51 \pm 30.64 in the patients. Other characteristics of the studied participants and their average anxiety scores are shown in Table 2.

According to Table 1, dental anxiety had a significant relationship with gender $(p<0.01)$, so that women perceived anxiety more than men. The mean scores of anxieties were not significantly different with regard to different factors such as the patients' education, type of employment, frequency of dental visits, ethnicity, and age $(p<0.001)$.

\section{Discussion}

The aim of this study was to evaluate the level of dental anxiety in patients. Based on the findings, the patients' dental anxiety mean 
Table 2. Frequency distribution of dental anxiety mean scores according to the participants' demographic characteristics who referred to dental clinics in Ahvaz in 2020

\begin{tabular}{|c|c|c|c|c|}
\hline \multicolumn{2}{|c|}{ Demographic variables } & \multirow{2}{*}{$\begin{array}{c}\text { Frequency (\%) } \\
74(18.6)\end{array}$} & \multirow{2}{*}{$\begin{array}{c}\text { Dental anxiety means } \\
\text { scores } \\
87.77 \\
\end{array}$} & \multirow{2}{*}{$\begin{array}{c}P \text {-value } \\
\text { (statistical test) } \\
p=0.589\end{array}$} \\
\hline Age & $18-30$ years & & & \\
\hline & 31-40 years & $104(26.2)$ & 89.92 & \\
\hline & $41-50$ years & $125(31.5)$ & 85.77 & \\
\hline & $51-60$ years & $82(20.7)$ & 85.34 & \\
\hline & 60 years and over & $12(3)$ & 97.83 & \\
\hline \multirow[t]{2}{*}{ Gender } & Male & $151(38)$ & 82.15 & \multirow{2}{*}{$\begin{array}{c}p<0.006^{\star} \\
\text { Independent }-T\end{array}$} \\
\hline & Female & $246(62)$ & 90.80 & \\
\hline \multirow[t]{3}{*}{ Education } & Illiterate & $3(0.8)$ & 107.67 & \multirow{3}{*}{$\begin{array}{c}p=0.348 \\
\text { One-way ANOVA }\end{array}$} \\
\hline & Primary school-Diploma & $54(13.6)$ & 90.83 & \\
\hline & Academic & $340(85.6)$ & 89.80 & \\
\hline \multirow[t]{5}{*}{ Occupation } & Self-employed & 49 (12.3) & 85.78 & \multirow{5}{*}{$\begin{array}{c}p<0.215 \\
\text { One-way ANOVA }\end{array}$} \\
\hline & House-keeper & $81(20.4)$ & 91.63 & \\
\hline & Worker & $9(2.3)$ & 80.56 & \\
\hline & Employee & $173(43.6)$ & 89.35 & \\
\hline & Others & $85(21.4)$ & 81.55 & \\
\hline \multirow[t]{6}{*}{ Ethnicity } & Bakhtiyari & $97(24.4)$ & 86.77 & \multirow{6}{*}{$\begin{array}{c}p=0.665 \\
\text { One-way ANOVA }\end{array}$} \\
\hline & Turkish & $17(4.3)$ & 75.82 & \\
\hline & Arab & 49 (12.3) & 88.51 & \\
\hline & Fars & $187(47.1)$ & 88.88 & \\
\hline & Lori & $27(6.8)$ & 74.78 & \\
\hline & Others & $20(5)$ & 89.40 & \\
\hline \multirow{3}{*}{$\begin{array}{l}\text { History of } \\
\text { referrals }\end{array}$} & Once at most & $315(79.3)$ & 87.50 & \multirow{3}{*}{$\begin{array}{c}p=0.516 \\
\text { One-way ANOVA }\end{array}$} \\
\hline & 2-6 times & $66(16.6)$ & 89.47 & \\
\hline & More than 6 times & $16(4)$ & 79.63 & \\
\hline
\end{tabular}

${ }^{*} p<0.05$

scores were lower than the DAI mean scores, which is similar to the results of other studies (Fayad et al. 2017; Muhannad et al. 2020; Yaghooti Khorasani 2014; Morovati Sharif et al. 2012; Sharifi 2011). We also found that more than $20 \%$ of the patients had two to six dentistry referrals. Although dental anxiety of our patients was not at a significant level, the measured level of anxiety can be of great importance since the patients' anxiety level did not change significantly with a higher number of visits to the dentist $(p=0.516)$. Although the highest mean anxiety scores were among the illiterate and the elderly, this difference was not statistically significant among different age groups ( $p=0.589$ ). Therefore, these findings should be considered further in future studies. In other words, these insignificant results can be explained by the small number of illiterate participants and those over 60 years of age in this study. Consequently, future studies using appropriate sample size and among different age groups may result in more accurate findings (Javadinejad et al. 2013) with regard to different anxiety levels among the elderly or the illiterate individuals (because no significant difference was observed in anxiety scores of participants from different educational groups; $p=0.348$ ). This finding can also be explained by noting that the variables related to illiteracy were only related to the elderly participants in this research. This indicates a limitation of our study with regard to the sampling method in terms of the research objectives. So, future researchers are suggested to study the existence or severity of the relationship of anxiety with education and age variables.

Based on the findings, the dental anxiety scores were significantly different between men and women $(p<0.01)$, indicating that women suffer from higher levels of anxiety in visiting the dentist. This finding is supported by most similar studies conducted in different countries (Fayad et al. 2017; Javadinejad et al. 2013; Eroglu et al. 2013; Freeman 1985), which shows the importance of gender and its effect on the level of dental anxiety. Consequently, women should 
receive priority in educational and interventional programs in this field.

Based on the findings, no significant relationship was found between the patients' dental anxiety and variables such as education, ethnicity, age, referral history, and employment $(p<0.05)$. However, these results are not completely consistent with other studies (Saberi and Nahash 2018; Muhannad et al. 2020; Sharifi 2011; Santos 2020), which means that demographic factors have no significant relationship and do not play an effective role in dental anxiety. Therefore, it is better to investigate stronger and more predictive environmental-social variables related to the dentistry or service providers, such as dentists. In line with other similar studies, we found that factors resulting from managing the clinics and therapeutic factors related to the dentists and environment are of great importance (Farhadi Nasab 2009; Grath and Bedi 2004).

Finally, despite the small effect of demographic variables, it can be argued that female gender and other environmental factors are probably more decisive, compared with other demographic factors, for dental anxiety. Some experts, including Eroglu, believe that the two variables of female gender and sociocultural factors play the most important role in dental anxiety, which is in line with our findings (Eroglu et al. 2017).

\section{Study limitations}

Since the questionnaires were completed based on information provided by the individuals themselves and the number of questions was high, the results may have been influenced by the individuals' situation and their psychological issues in answering the questionnaires. Furthermore, the study sample size, location, and specific dentistry facilities may limit the generalizability of the study results.

\section{Conclusions}

Findings of the study showed that the level of dental anxiety was significantly different among the participants based on their gender, so that women tolerate higher levels of anxiety. So, authorities are suggested to prioritize their interventions to manage dental anxiety, especially among women.

\section{Ethics approval and consent to participate}

In order to observe ethical considerations, all participants were assured that their information would remain confidential and all questionnaires were coded to this end. Moreover, the participants were clearly explained about the study objectives and finally those who were willing to participate were enrolled. This study was also approved in the Ethics Committee of Ahvaz Jundishapur University of Medical Sciences with the Ethics Code of IR.AJUMS. REC.1399.113.

\section{Availability of data and materials}

Upon request, we can offer onsite access to external researchers to the data analyzed at Ahvaz Jundishapur University of Medical Sciences, Ahvaz, Iran. To do so, Dr. Maria Cheraghi should be contacted.

\section{Acknowledgements}

This study was as part of dissertation by Ms. Elaheh Mali in the school of dentistry. This study was supported by the Social Determinants of Health Research Center in Ahvaz Jundishapur University of Medical Sciences, Ahvaz, Iran (SDH-9906). The authors would like to express their gratitude to all participants for their cooperation in this study.

\section{Disclosure}

The authors declare no conflict of interest.

\section{References}

1. Addicks SH, McNeil DW, Randall CL, et al. Dental carerelated fear and anxiety: distress tolerance as a possible mechanism. JDR Clin Trans Res 2017; 2: 304-311.

2. Bracha S, Vega E, Vega C. Posttraumatic dental-care anxiety: is "dental phobia" a misnomer? Hawaii Dental J 2006; 37: 17-19.

3. Cheraghi M, Najafian M, Amoori N, et al. Risk factors of postpartum depression in Ramhormoz city, Iran. Neuropsychiatria i Neuropsychologia 2015; 10: 1-4.

4. Eroglu CN, Ataoglu H, Kucuk K. Factors affecting anxietyfear of surgical procedures in dentistry. Niger I Clin Pract 2017; 20: 409-414.

5. Farhadi Nasab A. Anxiety and its causes in patients referring to Hamedan Public Dental Office in 2005. Journal of Dentistry, Tehran University of Medical Sciences and Health Services 2009; 21: 25-31.

6. Fayad M, Elbieh A, Baig M, Alruwaili SA. Prevalence of dental anxiety among dental patients in Saudi Arabia. J Int Soc Prev Community Dent 2017; 7: 100-104.

7. Freeman R. Dental anxiety: a multifactorial aetiology. Br Dent J 1985; 159: 406-408.

8. Gelder MJ, Andreasen NC, Lopez-ibor JJ. New Oxford textbook of psychiatry. Oxford University Press 2009.

9. Grath C, Bedi R. The association between dental anxiety and oral health-related quality of life in Britain. Community Dent Oral Epidemiol 2004; 32: 67-72. 
10. Goudarzi G, Alavi N, Geravandi S, et al. Ambient particulate matter concentration levels of Ahvaz, Iran, in 2017. Environ Geochem Health 2019; 41: 841-849.

11. Halonen $\mathrm{H}$, Nissinen J, Lehtiniemi $\mathrm{H}$, et al. The association between dental anxiety and psychiatric disorders and symptoms: a systematic review. Clin Pract Epidemiol Ment Health 2018; 14: 207-222.

12. Jamshidi M, Nazari I, Malayeri HT, et al. Pattern of drug abuse in addicts self-referred drug rehabilitation centers in Khuzestan province - Iran, 2014-2015. Arch Med Sadowej Kryminol 2016; 66: 1-12.

13. Javadinejad SH, Ghasemi D, Yazdi F. The relationship be tween dental fear in children ages 6 to 8 with fear of their parents. The relationship between dental fear in children ages 6 to 8 with fear of their parents. Knowl Res Appl Psychol 2013; 14: 54-58, 91

14. Mehrstedt M, Tonnies S, Eisentraut I. Dental fear, health status, and quality of life. Anesth Prog 2004; 51: 90-94.

15. Mohammed RB, Lalithamma T, Varma DM, et al. Prevalence of dental anxiety and its relation to age and gender in coastal Andhra (Visakhapatnam) population, India. J Nat Sci Biol Med 2014; 5: 409-414.

16. Morovati Sharif A, Bad MA, Haerian Ardakani A, Falahzade $\mathrm{H}$. Evaluation of dental anxiety in patients referred to private dental offices in Mashhad. Journal of Yazd School of Public Health 2012; 35: 42-49.

17. Muhannad H, Navin A, Mansour K. Evaluating factors associated with fear and anxiety to dental treatment - a systematic review. J Family Med Prim Care 2020; 9: 4530-4535

18. Saatchi M, Abtahi M, Mohammadi G, et al. The prevalence of dental anxiety and fear in patients referred to Isfahan Dental School, Iran. Dent Res J (Isfahan) 2015; 12: 248-253.

19. Saberi V, Nahash B. Dental anxiety and its related factors in patients referred to the Faculty of Science and Services. Dentistry Journal of Guilan University of Medical Sciences 2018; 27: 9-16.

20. Santos HLF, Barreto JO, Brito Bastos CF, et al. Factors in fluencing fear and anxiety in patients undergoing mino oral surgery and dental implants: a literature review. Res Soc Develop 2020; 9: e544996657.

21. Sharifi HP. Principles of psychometric and psychological testing Tehran. Roshd publisher 2011. 14th ed.

22. Stouthard ME, Hoogstraten J. Prevalence of dental anxiety in the Netherlands. Community Dent Oral Epidemio 1990; 18: 139-142.

23. Tellez M, Kinner DG, Heimberg RG, et al. Prevalence and correlates of dental anxiety in patients seeking denta care. Community Dent Oral Epidemiol 2015; 43: 135-142.

24. Udoye $\mathrm{Cl}$, Oginni AO, Oginni FO. Dental anxiety among patients undergoing various dental treatments in a $\mathrm{Ni}$ gerian teaching hospital. J Contemp Dent Pract 2005; 6: 91-98.

25. Yaghooti Khorasani MM, Sistani F. Dental fear and anxiety among students of Rafsanjan University of Medical Sciences. Quarterly Journal of Sabzevar University of Medical Sciences 2014; 21: 1.

26. Yousefi R, Piri F. Psychometric properties of Dental Anxiety Inventory. J Mashhad Dental School 2017; 41: 69-78. 